\title{
Determinant of Low Birth Weight Infants: A Matched Case Control Study
}

\author{
Rosnah Sutan*, Mazlina Mohtar, Aimi Nazri Mahat, Azmi Mohd Tamil \\ Department of Community Health, Universiti Kebangsaan Malaysia Medical Centre (UKMMC), Kuala Lumpur, \\ Malaysia \\ Email: rosnah sutan@yahoo.com
}

Received 15 January 2014; revised 16 February 2014; accepted 28 February 2014

Copyright $@ 2014$ by authors and Scientific Research Publishing Inc.

This work is licensed under the Creative Commons Attribution International License (CC BY). http://creativecommons.org/licenses/by/4.0/

(c) ()

\begin{abstract}
Background: Low birth weight (LBW) is a well-known factor associated with neonatal mortality and has contributed to a range of poor health outcomes. Thus, the objective of this study was to determine factors associated with LBW infants. Methods: A matched case control study was conducted in Universiti Kebangsaan Malaysia. Data of deliveries were obtained from Total Hospital Information System and medical records. All registered deliveries from January to June 2012 were used as sample populations. There were 180 pairs of cases and controls matched on babies' gender. Fourteen variables were analyzed: maternal age, ethnicity, gravida, parity, gestational age, maternal booking weight, height and body mass index (BMI), history of low birth weight infants, birth interval, booking hemoglobin levels, hypertension, diabetes mellitus and mode of delivery. Results: Younger mother $(t=6.947, p<0.001)$, lower booking BMI $(t=3.067, p=0.002)$, prematurity $(t=12.324, p<0.001)$, history of LBW infants $(O R=3.0, p=0.001)$, LSCS (OR $=0.06, p=$ $0.001)$ and current hypertension $(O R=3.1, p=0.008)$ were found significant in bivariate analysis. Multivariable conditional logistic regression identified younger maternal age $(A O R=2.9,95 \% \mathrm{CI}=$ $1.86-4.51, p<0.001)$, previous history of $L B W$ infants $(A O R=3.7,95 \% \mathrm{CI}=1.03-13.58, \mathrm{p}=$ $0.045)$, prematurity $(A O R=2.4,95 \% \mathrm{CI}=1.79-3.26, \mathrm{p}<0.001)$, and current hypertension $(\mathrm{AOR}=$ $4.5,95 \% \mathrm{CI}=1.06-19.22, \mathrm{p}=\mathbf{0 . 0 4 1}$ ) as significant factors associated with $\mathrm{LBW}$ infants. Conclusion: Younger maternal age, history of LBW infants, prematurity and hypertension have been recognized as predictors of LBW infants. The importance of pre-pregnancy screening, early antenatal booking and proper identification of high risk-mother needs to be strengthened and enforced in effort to reduce incidence of LBW infants.
\end{abstract}

\section{Keywords}

Low Birth Weight; Maternal Factors; Matched Case Control

\footnotetext{
${ }^{*}$ Corresponding author.
} 


\section{Introduction}

Birth weight is the first weight of the fetus or newborn obtained soon after the birth. It should be ideally measured within the first hour of life to avoid significant postnatal weight loss occurring. Low birth weight (LBW) is defined as weight at birth of less than 2500 gram while very low birth weight (VLBW) is defined as birth weight of less than 1500 grams. It is primarily resulted from either prematurity (birth before 37 weeks of gestation) or intrauterine growth restriction (IUGR) [1].

The World Health Organization (WHO) has reported that the prevalence of low birth weight infants is $15.5 \%$ or approximately 20 million of all births and common in developing countries. The LBW rate was $16.5 \%$ in developing countries and 7\% in developed countries. Half of all LBW infants are born in South Central Asia and more than $27 \%$ of all neonates in these countries are LBW [1].

Low birth weight is a known factor associated with neonatal mortality and morbidity and has contributed to a range of poor health outcomes. LBW contributes to growth impairment and poor cognitive development. Infant of LBW has potential to develop chronic diseases later in life. Low birth weight is now known to be associated with increased rates of coronary heart disease and the related disorders, stroke, hypertension and adult-onset diabetes [2] [3]. A study done in India found that the prevalence of VLBW infants was $4 \%-7 \%$ of all live births and contributed to nearly $30 \%$ of early neonatal death [4]. For Malaysia, low birth weight infants contributed to $74.8 \%$ of all infant deaths, with the highest death rate being among Indians, followed by Malays, and Chinese, respectively [5].

The LBW rate is a good health indicator of public health problem including long-term maternal malnutrition, ill health and poor health care. Low birth weight is an important predictor of newborn health and survival. Based on epidemiological observations, low birth weight infants are 20 times likely to develop complications compared to heavier babies [1]. LBW together with preterm delivery has also been recognized as a strong biological predictor of unfavorable developmental outcomes [6]. Among the health disadvantages associated with low birth weight, there were cognitive deficits, motor delays, cerebral palsy, and other behavioral and psychological problems [7] [8].

Many studies have identified prevalence and risk factors associated with low birth weight worldwide. A recent study done in Pakistan has reported that teenage mother, low maternal education, poor antenatal care, maternal anemia, and pregnancy-induced medical ailments have a strong association with low birth weight [9]. Extreme maternal age (less than 18 years old and more than 35 years old) and lower parity have shown significant association with low birth weight infants [10]. A number of studies have shown correlates of antenatal care, parity, inter pregnancy interval, gestational weight and bad obstetric history with occurrence of low birth weight infants [11]-[15].

A study conducted in one of tertiary hospitals in Malaysia showed an association of older age (35 years and above), low pre-pregnancy BMI $\left(<20 \mathrm{Kg} / \mathrm{m}^{2}\right)$, parity of 4 and above, Indian origin, economically under privileged, and abnormal blood pressure as risk factors associated with low birth weight [16]. A study done in secondary hospital in Malaysia revealed that the prevalence of low birth weight infants was $12.6 \%$ in year 2006 and the significant risk factors associated were gestational age, maternal pre-pregnancy weight, nulliparity, previous history of low birth weight infants and pregnancy-induced hypertension during current pregnancy [17].

Many efforts have been done to study on the epidemiology of low birth weight, but the prevalence of LBW infants in Malaysia is still remained between 11 - 14 percent for the last 12 years. An old study done in 1991 at Kuala Lumpur Hospital reported that the prevalence of LBW was 13.5\% [5] while recent study in Seremban Hospital showed a prevalence of low birth weight infants of 13.96\% in 2008 [16]. However, those were institutional-based study. The prevalence of LBW in Malaysian population was 11.1\% in 2011 [18]. This plateau prevalence pattern calls for further studies to be done in identifying the root causes as LBW is still remain a significant health problem.

The goal of reducing low birth weight incidence by at least one third between 2000 and 2010 is one of the major goals in "A World Fit for Children", the Declaration and Plan of Action adopted at the United Nations General Assembly Special Session on Children in 2002 [1]. The reduction of low birth weight is an important contribution to the achievement of Millennium Development Goal (MDG) for reducing child mortality. Activities towards the achievement of the MDGs will need to ensure a healthy start in life for children by making that women commence pregnancy healthy, well nourished, and go through pregnancy and childbirth safely. Low birth weight is therefore an important indicator for monitoring progress towards this internationally agreed-upon 
goal.

As a public health priority and the importance to prevent the occurrence of low birth weight infants, this study aims to identify factors associated with low birth weight infants in UKMMC. By identifying the predictors of the low birth weight, preventive action can be taken to reduce the number of neonatal death and morbidity associated with low birth weight.

\section{Material and Methods}

A matched case control study was conducted at UKMMC in Kuala Lumpur, Malaysia. List and data of deliveries were obtained from Total Hospital Information System (THIS). Ethical approval was obtained from Universiti Kebangsaan Malaysia Research Ethics Committee (UKMREC) and was conducted in accordance to Good Clinical Practice (GCP) requirements.

All registered deliveries from January 2012 to June 2012 were used as sample population with a total of 3214 infants. Among them, 356 infants were delivered with low birth weight. Infants born with unknown gestational age $(n=2)$, multiple pregnancy $(n=82)$, ambiguous or unknown genitalia $(n=8)$ and stillbirth $(n=19)$ were excluded from this study. We also excluded infants delivered by non-citizen mother $(n=161)$ and unknown maternal age $(n=8)$.

There were a total of 2934 eligible samples with 279 low birth weight infants. By using simple random sampling by SPSS, 180 infants with low birth weight were taken as cases. For each case of low birth weight infant identified, one control infant was selected randomly using SPSS random sampling from all infants with birth weight of $>2500$ grams born on the same period in the hospital. The control was matched with babies' sex.

The data information gathered from THIS were reconfirmed and additional data taken by retrieving maternal health records. Information obtained was entered into a standardized data sheet. The data sheet included the following information: maternal socio demographic and obstetrics information including age, ethnic group, height and weight at booking, gravid and parity, hemoglobin level at booking, history of low birth weight, medical problems, birth interval and illness during pregnancy. Information on infants was infant's birth weight, gestational age, gender and modes of delivery.

Maternal age was defined as age of the mother at the time of delivery. Race was based as recorded in the medical record. Maternal pre-pregnancy height (in $\mathrm{cm}$ ) and weight (in $\mathrm{Kg}$ ) were based on first maternal antenatal record during the first trimester or at hospital antenatal booking. Mothers' height was categorized into short stature $(\leq 145 \mathrm{~cm})$ and normal height if more than $145 \mathrm{~cm}$ as written in the mother's antenatal home based card. Body mass index (BMI) was calculated and classified according to World Health Organization classification [19]. Gravida was defined as the number of all previous pregnancies including abortion and stillbirths. Hemoglobin (Hb) level at booking was used.

Mother's medical illness was based on diagnosis written in the THIS and confirmed by information gathered from the medical health record. Medical problems and illness during pregnancy were recorded based on classification in International Code of Disease (ICD) $10^{\text {th }}$ revision [20]. Hypertension in this study was defined as all hypertensive related illnesses which include essential hypertension, gestational hypertension, pre-eclampsia and eclampsia. Diabetes mellitus (DM) was defined as pre existing DM and gestational DM.

Birth interval was defined as the period between previous delivery and recent conception. The birth interval was calculated in years and were group into $\geq 2$ years and $<2$ two years as written in the maternal home based card. History of LBW infants was defined as maternal history delivering LBW infants. Infant's gestational age was based on gestational age written in the medical record. Prematurity was defined as birth before completed 37 weeks of gestation. Mode of delivery was classified as vaginal delivery (including spontaneous vertex delivery, breech delivery and instrumental delivery or lower segment caesarean section (LSCS)). The mode of delivery is not contributed to LBW. However, birth weight normally determines the mode of delivery.

To determine the sample size, a power analysis for dichotomous variables was conducted in Power and Sample Size (PS) software version 3.0.43 following Dupont [21]. Assuming the proportion of infants with low birth weight in nulliparous mother to be $39.1 \%$ [10], a sample size of at least 152 in each group was needed to detect an odds ratio of 3.4 at $95 \%$ level of confidence with a power of $90 \%$ (two tails). As a result, 360 samples (180 cases and 180 controls) were taken as respondent with 1:1 matching according to babies' sex.

The statistical package SPSS version 20 was used for data analysis. Potential risk factors between cases and controls were compared. To measure the association between LBW and the risk factors, we conducted McNe- 
mar's test for categorical matched paired data. The paired $t$ test was used for comparison of continuous variables with normal distribution. Multivariable conditional logistic regression analysis was used to predict factors associated with low birth weight infants. Significant associations were taken at p values of less than 0.05 and $95 \%$ confidence interval.

\section{Result}

There were a total of 3214 infants delivered in University Kebangsaan Malaysia Medical Centre between January 2012 and June 2012. Among them, 356 infants were delivered with low birth weight giving a period prevalence of 11.08 percent. There were 180 subjects who met the definition for case group were selected and matched to controls based on the baby's gender.

Total samples in this study were 360 infants with 180 cases and 180 controls. Table 1 summarize the demographic characteristics of the respondents in term of age, race, gravid, parity, weight at booking, height, hemoglobin at booking, body mass index (BMI), gestational age, history of low birth weight baby, mode of delivery and medical illness including Diabetes Mellitus and hypertension. Babies' gender was the matching criteria for cases and control, thus it give the same number of 87 males and 93 females infants for each group. The mean birth weight for cases group was $2.10 \pm$ s.d.0.40 Kg while mean birth weight for control group was $3.16 \pm$ s.d.0.39 Kg.

Paired $t$ test was used to determine association between continuous variables in matched paired infants (Table 2). For maternal age, the mean age for mothers with low birth weight infants was lower (29.6 \pm s.d.4.63 years old) compared to mean age for control group (30.2 \pm s.d.3.96 years old) and statistically significant $(\mathrm{t}=6.947, \mathrm{p}<$ 0.001 , CI of mean difference $0.46-0.83$ ). Maternal weight at booking showed statistically significant difference when comparing between matched cases and control group $(\mathrm{t}=4.152, \mathrm{p}<0.001$, CI of mean difference 2.82 7.92). For gestational age, the mean gestational age for cases group was $35.80 \pm$ s.d.4.82 weeks while control group was $38.62 \pm$ s.d.1.33 weeks with significant paired $t$ test $(t=12.324, p<0.001$, CI of mean difference 2.37 - 3.27). No difference noted for hemoglobin level at booking in between cases (mean $=11.71 \pm$ s.d.1.15) and control group (mean $=11.76 \pm$ s.d.1.06).

Table 3 displays both concordant and discordant pairs for potential risk factors of low birth weight and the associations using McNemar test. Significant association was identified between LBW and prematurity ( $<$ < $0.001)$, history of low birth weight baby $(\mathrm{p}=0.001)$ and hypertension $(\mathrm{p}=0.008)$. It was found that mode of delivery $(\mathrm{p}<0.005)$ showed significant finding but actually the birth weight of the baby predicted the mode of delivery. Other risk factors such as race, gravid, parity, short stature, inter pregnancy interval, hypertension and Diabetes Mellitus were not found statistically significant.

To determine factors significantly contributed as predictors of LBW infants, exploratory multivariable conditional logistic regression analysis (Table 4) was conducted for matched pair data stratified by subjects. Result from backward stepwise conditional logistic regression, Omnibus Test of Model Coefficients indicated that maternal age, history of LBW, gestational age and hypertension were potentially important predictors of LBW ( -2 Log Likelihood $=85.03, X^{2}=109.78, \mathrm{p}<0.001$ ). Prematurity (born before completed 37 weeks of gestation) had 2.4 times at higher risk for LBW compared to term baby (born at $\geq 37$ weeks of gestation) (adjusted OR 2.41, 95\% CI 1.79 - 3.26, p < 0.001) when adjusted for maternal age, history of LBW and hypertension. Younger mothers had 2.89 times the odds to have LBW baby (adjusted OR 2.89, 95\% CI $1.86-4.51$, p < 0.001) when adjusted for history of previous LBW baby, gestational age and hypertension. A mother with history of LBW baby had a 3.74 times the odds to have LBW baby (adjusted OR 3.74, 95\% CI $1.03-13.58$, p = 0.045) when adjusted for maternal age, gestational age and hypertension. Hypertensive mother had 4.52 times the odds compared to non-hypertensive mother (adjusted OR 4.52, 95\% CI $1.06-19.22, \mathrm{p}=0.041$ ) when adjusted for maternal age, gestational age and history of LBW baby.

\section{Discussion}

The prevalence of LBW infants was $11.08 \%$ as identified in this study thus confirmed that LBW is still a major problem in Malaysia. Although it seem to be reducing trend compared to 13.96\% (year 2008) in previous studies [16], LBW is still remain a significant cause of morbidity and mortality among neonates and children [1] [4] [6]-[8]. This study showed the association between maternal socio demographic and obstetric factors on LBW infants in UKM Medical Center. 
Table 1. Characteristic of LBW cases and controls.

\begin{tabular}{|c|c|c|c|c|}
\hline \multirow{2}{*}{ Variables } & \multicolumn{2}{|c|}{ Cases (LBW Infants) } & \multicolumn{2}{|c|}{ Controls } \\
\hline & n (\%) & Mean (sd) & n (\%) & mean (sd) \\
\hline \multicolumn{5}{|l|}{ INFANTS } \\
\hline Birth Weight (Kg) & & $2.10(0.40)$ & & $3.16(0.39)$ \\
\hline \multicolumn{5}{|l|}{ Baby’s Gender } \\
\hline Boy & $87(48.3)$ & & $87(48.3)$ & \\
\hline Girl & $93(51.7)$ & & $93(51.7)$ & \\
\hline Gestation Age (Weeks) & & $35.80(2.97)$ & & $38.62(1.33)$ \\
\hline$<37$ & $92(51.1)$ & & $9(5.0)$ & \\
\hline$\geq 37$ & 88 (48.9) & & $171(95.0)$ & \\
\hline \multicolumn{5}{|l|}{ MOTHERS } \\
\hline Age (Years) & & $29.60(4.63)$ & & $30.24(3.96)$ \\
\hline \multicolumn{5}{|l|}{ Ethnic Group } \\
\hline Malays & $132(73.3)$ & & $135(75.0)$ & \\
\hline Non Malays & $48(26.7)$ & & $45(25.0)$ & \\
\hline \multicolumn{5}{|l|}{ Gravida } \\
\hline 1 & $85(47.2)$ & & $67(37.2)$ & \\
\hline$>1$ & $95(52.8)$ & & $113(62.8)$ & \\
\hline \multicolumn{5}{|l|}{ Parity } \\
\hline 0 & $94(52.2)$ & & $78(43.3)$ & \\
\hline$\geq 1$ & $86(47.8)$ & & $102(56.7)$ & \\
\hline Pre Pregnancy Weight (Kg) & & $56.91(13.26)$ & & $62.28(13.13)$ \\
\hline Pre Pregnancy Height (cm) & & $155.59(5.41)$ & & $157.49(6.12)$ \\
\hline \multicolumn{5}{|l|}{ Height Group (cm) } \\
\hline$\leq 145.0$ & $5(2.8)$ & & $4(2.2)$ & \\
\hline$>145.0$ & $175(97.2)$ & & $176(97.8)$ & \\
\hline $\operatorname{BMI}\left(\mathrm{Kg} / \mathbf{m}^{2}\right)$ & & $23.5(5.36)$ & & $25.06(4.82)$ \\
\hline \multicolumn{5}{|l|}{ History of LBW } \\
\hline Yes & $35(19.4)$ & & $13(7.2)$ & \\
\hline No & $145(80.6)$ & & $167(92.8)$ & \\
\hline \multicolumn{5}{|l|}{ Birth Interval (Years) } \\
\hline$<2$ & 35 (19.4) & & $38(21.1)$ & \\
\hline$\geq 2$ & $145(80.6)$ & & $142(78.9)$ & \\
\hline Hb at Booking (g/L) & & $11.7(1.16)$ & & $11.8(1.06)$ \\
\hline \multicolumn{5}{|l|}{ Hypertension } \\
\hline Yes & 25 (13.9) & & $10(5.6)$ & \\
\hline No & $155(86.1)$ & & $170(94.4)$ & \\
\hline \multicolumn{5}{|l|}{ Diabetes } \\
\hline Yes & $18(10.0)$ & & $23(12.8)$ & \\
\hline No & $162(90.0)$ & & $157(87.2)$ & \\
\hline \multicolumn{5}{|l|}{ Mode of Delivery } \\
\hline Non LSCS & $114(63.3)$ & & $174(96.7)$ & \\
\hline LSCS & 66 (36.7) & & $6(3.3)$ & \\
\hline
\end{tabular}


Table 2. Risk factors for LBW (univariable analysis).

\begin{tabular}{|c|c|c|c|c|c|c|}
\hline \multirow{2}{*}{ Variables } & \multicolumn{2}{|c|}{ Mean (sd) } & \multicolumn{2}{|c|}{ Paired Differences } & \multirow{2}{*}{$t(d f)$} & \multirow{2}{*}{ p-value } \\
\hline & Case & Control & Mean ( \pm sd) & $95 \% \mathrm{CI}$ & & \\
\hline Age (Years) & $29.60(4.63)$ & $30.24(3.96)$ & $0.64(1.25)$ & $0.46-0.83$ & $6.947(179)$ & $<0.001^{* * *}$ \\
\hline Mother's Weight (Kg) & $56.91(13.26)$ & $62.28(13.13)$ & $5.37(17.34)$ & $2.82-7.92$ & $4.152(179)$ & $<0.001+*$ \\
\hline BMI $\left(\mathrm{Kg} / \mathbf{m}^{2}\right)$ & $23.5(5.36)$ & $25.06(4.82)$ & $1.56(6.84)$ & $0.56-2.57$ & 3.067 (179) & $0.002^{* *}$ \\
\hline Gestational Age (Weeks) & $35.80(2.97)$ & $38.62(1.33)$ & $2.82(3.07)$ & $2.37-3.27$ & $12.324(179)$ & $<0.001 *$ \\
\hline Haemoglobin (g/L) & $11.7(1.16)$ & $11.8(1.06)$ & $0.05(1.58)$ & $-0.18-0.28$ & $0.439(179)$ & 0.661 \\
\hline
\end{tabular}

"Paired t-test, $\mathrm{CI}=$ Confidence Interval, ${ }^{* *}$ significant at $\mathrm{p}<0.05$.

Table 3. Mcnemar table for LBW case-control pairs (univariable analysis).

\begin{tabular}{|c|c|c|c|c|c|c|c|}
\hline \multirow{2}{*}{\multicolumn{2}{|c|}{ Control Group $(n=180)$}} & \multicolumn{4}{|c|}{ Case Group $(n=180)$} & \multirow{3}{*}{\begin{tabular}{|c|} 
p-value \\
0.801
\end{tabular}} & \multirow{3}{*}{$\begin{array}{c}\text { OR } \\
0.91\end{array}$} \\
\hline & & \multicolumn{2}{|c|}{ Yes n (\%) } & \multicolumn{2}{|c|}{ No n (\%) } & & \\
\hline \multirow{2}{*}{ Malay Ethnic } & Yes & 102 & $(56.7)^{\mathrm{a}}$ & 33 & $(18.3)^{\mathrm{c}}$ & & \\
\hline & No & 30 & $(16.7)^{\mathrm{b}}$ & 15 & $(8.3)^{d}$ & & \\
\hline \multirow{2}{*}{ Gravida 0} & Yes & 36 & $(20.0)$ & 31 & $(17.2)$ & 0.057 & 1.58 \\
\hline & No & 49 & $(27.2)$ & 64 & $(35.6)$ & & \\
\hline \multirow{2}{*}{ Para 0} & Yes & 44 & $(24.4)$ & 34 & (18.9) & 0.101 & 1.47 \\
\hline & No & 50 & $(27.8)$ & 52 & (28.9) & & \\
\hline \multirow{2}{*}{ Height $\leq 145 \mathrm{~cm}$} & Yes & 0 & $(0.0)$ & 4 & $(2.2)$ & 1.000 & 1.25 \\
\hline & No & 5 & (2.8) & 171 & $(95.0)$ & & \\
\hline \multirow{2}{*}{ Gestation Age $<37$ Weeks } & Yes & 5 & (2.8) & 4 & $(2.2)$ & $<0.001^{*}$ & 21.75 \\
\hline & No & 87 & $(48.3)$ & 84 & $(46.7)$ & & \\
\hline \multirow{2}{*}{ History of LBW } & Yes & 2 & (1.1) & 11 & $(6.1)$ & $0.001^{*}$ & 3.00 \\
\hline & No & 33 & $(18.3)$ & 134 & $(74.4)$ & & \\
\hline \multirow{2}{*}{ Birth Interval $<2$ Years } & Yes & 7 & (3.9) & 31 & $(17.2)$ & 0.795 & 0.90 \\
\hline & No & 28 & $(15.6)$ & 114 & $(63.3)$ & & \\
\hline \multirow{2}{*}{ Hypertension } & Yes & 3 & (1.7) & 7 & (3.9) & $0.008^{*}$ & 3.14 \\
\hline & No & 22 & $(12.2)$ & 148 & $(82.2)$ & & \\
\hline \multirow{2}{*}{ Diabetes } & Yes & 1 & $(0.6)$ & 22 & $(12.2)$ & 0.522 & 0.77 \\
\hline & No & 17 & (9.4) & 140 & $(77.8)$ & & \\
\hline \multirow{2}{*}{ Non LSCS Delivery } & Yes & 110 & $(61.1)$ & 64 & (35.6) & $<0.001^{*}$ & 0.06 \\
\hline & No & 4 & $(2.2)$ & 2 & (1.1) & & \\
\hline
\end{tabular}

${ }^{\mathrm{a}, \mathrm{d}}$ Concordance pairs, ${ }^{\mathrm{b}, \mathrm{c}}$ Discordance pairs, OR = Odds Ratio. Calculated manually (ratio of discordance pairs $=\mathrm{c} / \mathrm{b}$ ), Percentage presented as total percentage, ${ }^{*}$ significant at $\mathrm{p}<0.05$.

Table 4. Predictors of LBW by multivariable conditional logistic regression analysis.

\begin{tabular}{ccccc}
\hline Variable & B & Adj. OR $(\mathbf{9 5} \% \mathbf{C I})^{\mathbf{a}}$ & Wald (df) & p value \\
\hline Gestation Age & 0.881 & $2.41(1.79-3.26)$ & $33.113(1)$ & $<\mathbf{0 . 0 0 1}^{*}$ \\
Maternal Age & 1.063 & $2.89(1.86-4.51)$ & $21.957(1)$ & $<\mathbf{0 . 0 0 1}^{*}$ \\
Hypertension & 1.509 & $4.52(1.06-19.22)$ & $4.179(1)$ & $\mathbf{0 . 0 4 1}^{*}$ \\
History of LBW & 1.318 & $3.74(1.03-13.58)$ & $4.010(1)$ & $\mathbf{0 . 0 4 5}^{*}$ \\
\hline
\end{tabular}

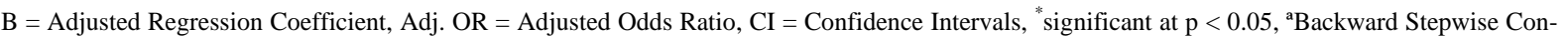
ditional Logistic Regression model was applied. Model assumptions are fulfilled. Interaction term were checked and not found. Omnibus Test of Model Coefficient p-value was $<0.001$ and -2 Log Likelihood $=85.033$. 
Maternal age was found significantly associated with low birth weight infants. The younger age group is at risk of having LBW babies compared to older age group and this finding is consistent with other studies [10] [13] [22]-[24]. However, there were also studies reported that the older maternal age is at higher risk in getting LBW infants [16]. The explanation could relate to maternal nutritional depletion that presence normally in teenage pregnancy and older age group because of poor eating pattern. Increased risk of chronic disease such as hypertension, Diabetes Mellitus and heart disease for advanced maternal age required them to deliver preterm or their babies developed intrauterine growth restriction due to poor maternal health.

The relationship between maternal booking body mass index (BMI) and fetal growth is well known [13] [18] [23]. Lower maternal BMI showed higher risk to have LBW infants. A study done by Yu et al. 2013 in China found that pre-pregnancy underweight will increase the risk of small for gestational age (SGA) and LBW infants while pre-pregnancy overweight and obesity will increases the risk of large for gestational age (LGA), macrosomia, and subsequent offspring overweight/obesity [25]. This finding may suggest the role of genetic influence in having LBW infants thus promoting for further research on possible of genetic involvement.

Low gestational age is a risk factor contributing to LBW infants [13] [17] [23] [26]. Gestational age plays an important role in determining infants' birth weight. Infants who are delivered prematurely (less than 37 weeks) are at higher risk to have low birth weight infants. The World Health Organization estimated about one third of low birth weight infants is caused by prematurity. With advanced technology, the prevalence of prematurity infants survived are increasing thus increased the number of LBW infants. This is one of the reasons identified why the prevalence of low birth weight infants remain unchanged since years ago. Thus, it is much more important in preventing the birth of premature baby by identifying and managing the associated risk factors.

Maternal obstetric factors such as gravida, parity, history of low birth weight, short stature, mode of delivery, inter pregnancy interval and medical illness such as hypertension and diabetes also play an important role in delivering healthy infants. Result of this study has shown, mother with history of LBW infants are having 4 times risk to get LBW infant compared to mothers with no history of LBW. Other studies were also reporting the same findings in their populations [17] [22].

Hypertensive mother had significant association with LBW infants in this study. Mother with essential hypertension, gestational hypertension, pre-eclampsia or eclampsia has 4.5 times higher risk for LBW infants. Gestational hypertension has a major influence on maternal and neonatal morbidity and mortality with approximately $6 \%$ - 8\% of all pregnancies is complicated by hypertensive disorders [27]. This condition can lead to a low birth weight for the baby or premature delivery which poses additional health risks to the child. If the hypertension becomes severe, it can lead to preeclampsia or eclampsia which can cause serious injuries or even death to both the mother and child. These results indicated that hypertensive disorders might play a critical role in the incidence of LBW as supported by other studies [17] [19] [28]. Evidence from earlier study showed that reduced placental blood flow leads to decreased fetal growth, with an increased risk of intrauterine growth restriction and low birth weight [29].

Delivery using lower segment caesarian section (LSCS) was found to have more risk in developing LBW compared to infants delivered via vaginal delivery. However, this association should be interpreted with caution as most of the mother needs to deliver by LSCS were complicated cases. They may need to undergone emergency LSCS due to threatened maternal condition but still in premature gestation such as severe pre-eclampsia, eclampsia and bleeding placenta praevia.

In this study, when we proceed for multivariable conditional logistic regression, LSCS was not found to be significant. Other obstetric risk factors such as gravida, parity, short stature, birth interval and medical illness such as diabetes and anemia were significant in this study. Other studies have shown that primigravida was found to be significantly associated with LBW [16] [22]. There was inconsistency in relating parity to occurrence of low birth weight. Boo et al. (2008) identified nulliparity as risk factors for low birth weight but other studies concluded multiparity as the associating factor [10] [16]. Syed and Kamathi (2012) concluded that maternal height has a direct effect on the weight of the newborn and proposed that maternal short stature be identified as an independent risk factor for LBW [30]. However, systematic review and meta-analyses of 84 studies (64 cohorts and 20 case-control) confirms that obesity and overweight in women was not protective against having LBW baby [31].

This study was unable to determine relationship between birth interval and LBW and has similarity with other study [17]. However, this factor cannot be excluded as one of the important predictors. There were few studies shown that birth interval had significant association with LBW [23] [32]. Instead, birth interval has become a 
major health promotion program strategy to improve mothers and children health in recent decades especially in developing countries. The birth interval has been reported to influence the outcome of pregnancy and birth. Too short and too long birth intervals have been associated with increased risk of a number of adverse perinatal outcomes, such as preterm birth, low birth weight, small size for gestational age, and perinatal death [33].

Some limitations identified in this study. Data were captured from tertiary hospital which normally received complicated cases. About 5\% of data were excluded for incompleteness after many attempts done for verification. There are also few variables such as other socio demographic characteristic such as maternal education level, paternal weight, smoking status of parents, occupation and drug ingestion that may have influence for LBW infants cannot be included in this study due to lacking of data. Exploring social determinants using population based study design would open up gaps in knowledge in this area.

\section{Conclusion}

Young maternal age, history of LBW infants, prematurity and having hypertension were identified as significant factors associated with LBW infants in UKMMC. This showed that these factors determine an important role for LBW infants. Therefore, the importance of pre-pregnancy screening, early antenatal booking and proper identification of high-risk mother needs to be strengthened and enforced in effort to reduce incidence of LBW infants. Efforts should focus on preventing or reducing incidence of pre-term delivery and hypertension (essential hypertension, gestational hypertension, pre-eclampsia and eclampsia) as these are recognized predictors for LBW infants. Effective health educations especially in promoting healthy wellbeing during pre-marital or prepregnancy care will help in detecting high-risk pregnancy that lead to LBW infants.

\section{Acknowledgements}

The authors thank to the Faculty of Medicine, Universiti Kebangsaan Malaysia for providing ethical approval and research grant to conduct this study. There is no conflict of interest of any parties contributing to this study.

\section{References}

[1] The United Nations Children’s Fund (UNICEF) (2004) Low Birth Weight: Country, Regional and Global Estimates. UNICEF, New York.

[2] Barker, D.J.P. (2004) The Developmental Origins of Chronic Adult Disease. Acta Paediatrica Supplement, 93, 26-33. http://dx.doi.org/10.1111/j.1651-2227.2004.tb00236.x

[3] Whincup, P., Cook, D., Papacosta, O. and Walker, M. (1995) Birth Weight and Blood Pressure: Cross Sectional and Longitudinal Relations in Childhood. BMJ, 311, 773-776. http://dx.doi.org/10.1136/bmj.311.7008.773

[4] Basu, S., Rathore, P. and Bhatia, B.D. (2008) Predictors of Mortality in Very Low Birth Weight Neonates in India. Singapore Medical Journal, 49, 556-560.

[5] Tahir, H.M., Ismail, N.N. and Gebbie, D.A. (1991) Low Birth Weight in Kuala Lumpur. Asia-Oceania Journal of Obstetrics and Gynaecology, 17, 135-142. http://dx.doi.org/10.1111/j.1447-0756.1991.tb00037.x

[6] Taylor, H.G., Minich, N.M., Klein, N. and Hack, M. (2004) Longitudinal Outcomes of Very Low Birth Weight: Neuropsychological Findings. Journal of the International Neuropsychological Society, 10, 149-163. http://dx.doi.org/10.1017/S1355617704102038

[7] Reichman, N.E. (2005) Low Birth Weight and School Readiness. Future Child, 15, 91-116. http://dx.doi.org/10.1353/foc.2005.0008

[8] Hack, M., Klein, N.K. and Taylor, H.G. (1995) Long-Term Developmental Outcomes of Low Birth Infants. Future Child, 5, 176-196. http://dx.doi.org/10.2307/1602514

[9] Fariha, A., Tahir, J., Afzal, M.F., et al. (2011) Maternal Risk Factors Associated with Low Birth Weight: A Case Control Study. ANNALS, 17, 223-228.

[10] Rakesh, K.N., Chandra, S.M., Maheshwar, D.M. and Vijaya, A.N. (2013) Prevalence of Low Birth Weight at Primary Health Center of North Karnataka. International Journal of Pharma Medicine \& Biological Science, 2, 1-4.

[11] Lopez, N.B. and Choonara, I. (2009) Can We Reduce the Number of Low-Birth-Weight Babies? The Cuban Experience. Neonatology, 95, 193-197. http://dx.doi.org/10.1159/000155649

[12] Negi, K.S., Kandpal, S.D. and Kukreti, M. (2006) Epidemiological Factors Affecting Low Birth Weight. JK Science, 8, 31-34.

[13] Agarwal, K., Agarwal, A., Agarwal, V.K., Agarwal, P. and Chaudhary, V. (2011) Prevalence and Determinants of Low 
Birth Weight among Institutional Deliveries. Annals of Nigerian Medicine, 5, 48-52. http://dx.doi.org/10.4103/0331-3131.92950

[14] Akin, Y., Cömert, S., Turan, C., Ünal, O., Piçak, A., Ger, L. and Telatar, B. (2010) Increasing Low Birth Weight Rates in Istanbul. Iranian Journal of Pediatrics, 20, 284-290.

[15] Zhu, B.P. (2005) Effect of Inter Pregnancy Interval on Birth Outcomes: Findings from Recent US Studies. International Journal of Obstetrics and Gynaecology, 89, 525-533. http://dx.doi.org/10.1016/j.ijgo.2004.08.002

[16] Yadav, H. and Lee, N. (2013) Maternal Factors in Predicting Low Birth Weight Babies. Medical Journal of Malaysia, 68, 44-47.

[17] Boo, N.Y., Lim, S.M., Koh, K.T. and Ravindran, J. (2008) Risk Factors Associated with Low Birth Weight Infants in the Malaysian Population. Medical Journal of Malaysia, 63, 306-310.

[18] Department of Statistics Malaysia (2012) Vital Statistics Malaysia 2011. Department of Statistics Malaysia, Putrajaya.

[19] World Health Organization (1995) Physical Status: The Use and Interpretation of Anthropometry. Report of a WHO Expert Committee, WHO Technical Report Series 854, World Health Organization, Geneva.

[20] World Health Organization (1993) International Statistical Classification of Diseases and Related Health Problems 10th Revision. WHO, Geneva, 129-130.

[21] Dupont, W.D. (1998) Power Calculation for Matched Case-Control Studies. Biometrics, 44, 1157-1168. http://dx.doi.org/10.2307/2531743

[22] Davoudi, N., Khezri, M., Asgarpour, M., Khatami, S.M., Hoseinpour, M. and Azarian, A.A. (2012) Prevalence and Related Factors of Low Birth Weight in Mashhad, Iran. Iranian Journal of Neonatology, 3, 69-76.

[23] Phalke, D., Phalke, D.B., Bangal, V.B., Avachat, S.S., Deshpande, J.D. and Palve, S.B. (2012) A Cross Sectional Study of Maternal Factors Influencing Low Birth Weight. Indian Medical Gazette, 226-228.

[24] Ryan, J.A., Casapia, M., Aguilar, E., Silva, H., Rahme, E., Gagnon, A.J., et al. (2011) A Comparison of Low Birth Weight among Newborns of Early Adolescents, Late Adolescents, and Adult Mothers in the Peruvian Amazon. Maternal Child Health Journal, 15, 587-596. http://dx.doi.org/10.1007/s10995-010-0621-8

[25] Yu, Z., Han, S., Zhu, J., et al. (2013) Pre-Pregnancy Body Mass Index in Relation to Infant Birth Weight and Offspring Overweight/Obesity: A Systematic Review and Meta-Analysis. PLoS ONE, 8, e61627. http://dx.doi.org/10.1371/journal.pone.0061627

[26] Moraes, A.B., Zainini, R.R., Riboldi, J. and Giugliani, E.R. (2012) Risk Factors for Low Birth Weight in Rio Grande do Sul State, Brazil: Classical and Multi-Level Analysis. Cadernos de Saúde Pública, Rio de Janeiro, 28, 2293-2305.

[27] Bujold, E., Roberge, S., Lacasse, Y., et al. (2010) Prevention of Preeclampsia and Intrauterine Growth Restriction with Aspirin Started in Early Pregnancy: A Meta-Analysis. Obstetrics \& Gynecology, 116, 402-414. http://dx.doi.org/10.1097/AOG.0b013e3181e9322a

[28] Yihua, B., Zhan, Z., Qiao, L., et al. (2013) Maternal Risk Factors for Low Birth Weight for Term Births in a Developed Region in China: A Hospital-Based Study of 55,633 Pregnancies. The Journal of Biomedical Research, 27, 14-22. http://dx.doi.org/10.7555/JBR.27.20120046

[29] Xiong, X., Demianczuk, N.N., Saunders, L.D., Wang, F.L. and Fraser, W.D. (2002) Impact of Preeclampsia and Gestational Hypertension on Birth Weight by Gestational Age. American Journal of Epidemiology, 155, 203-209. http://dx.doi.org/10.1093/aje/155.3.203

[30] Syed, W. and Kamathi, V.C. (2012) Maternal Short Stature: A Risk Factor for Low Birth Weight in Neonates. Journal of Medical \& Allied Science, 2, 62-65.

[31] McDonald, S.D., Han, Z., Mulla, S. and Beyene, J. (2010) Overweight and Obesity in Mothers and Risk of Preterm Birth and Low Birth Weight Infants: Systematic Review and Meta Analyses. BMJ, 341, c3428. http://dx.doi.org/10.1136/bmj.c3428

[32] Bener, A., Mohammed Saleh, N., Khalil Salameh, K.M., Basha, B., Joseph, S., Samson, N., et al. (2012) The Impact of the Inter Pregnancy Interval on Birth Weight and Other Pregnancy Outcomes. Revista Brasileira de Saúde Materno Infantil, 12, 233-241. http://dx.doi.org/10.1590/S1519-38292012000300003

[33] King, J.C. (2003) The Risk of Maternal Nutritional Depletion and Poor Outcome Increases in Early or Closely Spaced Pregnancies. Journal of Nutrition, 133, 1732S-1736S. 